Dosier

\author{
Bioética de otro \\ modo o cómo vivir \\ con máquinas, \\ humanos y otros \\ animales

\section{Bioethics Otherwise, or, How to Live with Machines, Humans, and Other Animals}

\author{
Joanna Zylinska* \\ GoldsMiths University OF LONDON \\ Inglaterra \\ Traducción de Deni Garciamoreno Becerril \\ denigarciamoreno.b@gmail.com \\ UNIVERSIDAD IBEROAMERICANA \\ México
}

\footnotetext{
* Este artículo fue originalmente publicado en Telemorphosis: Theory in the Era of Climate Change, vol. 1, editado por Tom Cohen (Michigan: University of Michigan Library, 2012). Se encuentra disponible en https://quod.lib.umich.edu/o/ohp/10539563.0001.001/1:11/--telemorphosis-theory-in-the-era-ofclimate-change-vol-1? rgn=div 1 ; view=fulltext
} 
Pues el pensamiento de lo animal, si es que tal cosa existe, proviene de la poesía. Ahí tienes una tesis: es aquello de lo que la filosofía, esencialmente, ha tenido que privarse.

JaCQues DerRIDA, El animal que luego estoy si(gui)endo

Parece que un animal está en el mundo como agua en el agua. Bojan Šarčević, proyecto de video, Garerie BQ, Colonia

Nunca quise ser poshumana, o poshumanista, más de lo que quise ser posfeminista.

Donna Haraway, When Species Meet

\begin{abstract}
Alas rotas
¿De qué manera puede hablar el ser humano a la sombra de la crítica poshumanista? Este ensayo surge de un momento prolongado de duda, de una confusión cognitiva y afectiva sobre la ontología y el estatus de aquello denominado "hombre". Ahora bien, claramente la confusión no es novedosa, ha sido inherente a la investigación disciplinar dentro de las humanidades, y en particular a la investigación asociada, durante las últimas décadas, al posestructuralismo filosófico. A inicios del siglo xxi, han contribuido aún más a la incertidumbre en torno al "hombre" los intentos de dar un giro hacia un involucramiento más serio de las humanidades con aquellas ciencias duras que tratan diferentes partes y partículas humanas —anatomía, neurología, genética一, así como el descubrimiento de que los típicos puntos de medición del ser humano, como el lenguaje, el uso de herramientas, la cultura (o "dejar rastros") y
\end{abstract}


las emociones en realidad cruzan la barrera de las especies. ${ }^{1}$ En lugar de intentar determinar la identidad del animal humano/no humano en todas sus configuraciones biodigitales, me interesa discutir en este ensayo de qué manera la comprensión transformada del humano puede ayudarnos no sólo a pensar mejor sobre nosotros mismos y otros que pueden o no ser como nosotros, sino también a vivir mejor con otros - máquinas, humanos y otros animales. El énfasis de esta investigación recae entonces más en la pragmática del "cómo", que en la naturaleza del "nosotros". Por lo tanto, mi enfoque aquí es sobre todo ético en lugar de ontológico. La mera investigación sobre las formas de vivir bien debe acompañarse por un examen tanto de quién llevará a cabo los modos de vivir como de quién va a involucrarse en el proceso de juzgar la bondad de esos modos y en la estructuración de un discurso teórico alrededor de nuestras formas biológicas y políticas de existencia.

En cierto sentido este ensayo es un intento de regresar al humano "después del cyborg". ${ }^{2}$ Es un intento apuntalado por un imperativo intelectual $y$, me atrevo a decir, personal, de encontrar una salida a lo que considero el impasse poshumanista de algunas tendencias en la teoría cultural contem-

\footnotetext{
${ }^{1}$ Para una discusión sobre cómo los rasgos y los comportamientos que eran concebidos como exclusivamente humanos ya han sido identificados a través de toda la barrera de las especies, ver Cary Wolfe, "In Search of Post-Humanist Theory: The Second-Order Cybernetics of Maturana and Varela", The Politics of Systems and Environments, parte I, número especial de Cultural Critique 30 (verano de 1995), 35; y Matthew Calarco, Zoographies: The Question of the Animal from Heidegger to Derrida (Nueva York: Columbia University Press, 2008), 3.

${ }^{2}$ Esta figura del cyborg, prestada del ciber-feminismo, ha sido un concepto importante en mi trabajo. En mis obras On Spiders, Cyborgs and Being Scared: The Feminine and the Sublime y en The Cyborg Experiments: Extensions of the Body in the Media Age, el cyborg funcionó como la figura híbrida y material, señala la bondad humana con otras criaturas, así como la dependencia humana hacia la tecnología —o lo que el filósofo Bernard Stiegler llama la técnica originaria-. Tal vez el poder de esta metáfora se ha gastado un poco, y no sólo por transitoriedad de las modas académicas con las metáforas y los conceptos. Si bien para mí los cyborgs siempre han sido técnicos y procesuales, me preocupa que mi uso continuo de este concepto pueda darles demasiados argumentos a los que proponen muchas teorías fluidas de las combinaciones humano-máquina, donde la metáfora general del fluido parece haber desaparecido de cualquier entidad o ser específico. La defensa o crítica del cyborg como una entidad singular no es mi objetivo principal en este ensayo. Más bien, mis esfuerzos surgen de mi insatisfacción con algunos aspectos de la teoría relacional de llegar-a-ser, los cuales, a veces, nos llevan a una disolución prematura de las diferencias entre los seres, las especies y las categorías — por eso mi regreso aquí al humano después del cyborg.
} 
poránea, a través de las cuales la propagación de nociones de relacionalidad transhumana, parentesco entre especies y devenir maquínico parece haber disminuido la necesidad de un cuestionamiento más riguroso de la singularidad de la diferencia entre especies (trans) y dentro de las especies (intra). Es por ello que me dispongo a explorar estas cuestiones, armada con las herramientas analíticas de la duda y la singularidad, en combinación con el uso intransigente del pronombre "yo", que de manera simultanea socava y reafirma mi pretensión humanista. Obviamente existe también la posibilidad de que este cuestionamiento a la vez poshumano y demasiado-humano sea sólo un ejercicio más de narcisismo, otro intento desesperado de regresar al yo y aferrarse a una fantasía de excepcionalidad humana. En este contexto, la pregunta hecha por Jacques Derrida, “ ¿existe el narcisismo animal?” se convierte en una especie de acusación, tal vez dirigida a aquellos de nosotros que todavía estamos obsesionados con la pregunta cartesiana: "Pero en cuanto a mí, ¿quién soy yo?”. ${ }^{3}$

Después de Freud, la fantasía del excepcionalismo humano se conserva con dificultad, tal y como Donna Haraway lo explica conmovedoramente en su libro When Species Meet. Las tres grandes heridas inflingidas al narcisismo primario del ser humano - a saber, la revolución copernicana, la teoría darwinista de la evolución y la excavación freudiana del inconsciente- han desestabilizado seriamente el egocentrismo geográfico, histórico y psíquico de la humanidad. ${ }^{4}$ A ellas Haraway añade una cuarta herida "informática o cyborgiana", "que despliega una carne orgánica y tecnológica". 5 Como resultado, el ser humano tiene que pensarse a sí mismo como ya desde siempre tecnológico, es decir, co-constituido y en co-evolución con el mundo conformado por entidades animadas e inanimadas. Para explicar este proceso performativo, Haraway recurre a

\footnotetext{
${ }^{3}$ Jacques Derrida, The Animal That Therefore I Am, trad. Marie-Louise Millet (Nueva York: Fordham University Press, 2008), 51-52.

${ }^{4}$ Aquí, Haraway confronta el ensayo de Derrida "And Say the Animal Responded?", expuesto como una ponencia en 1997 e incluido en El animal que luego estoy si(gui)endo.

${ }^{5}$ Donna Haraway, When Species Meet (Minneapolis y Londres: University of Minnesota Press, 2008), 12.
} 
la metáfora del baile y propone que este proceso de co-constitución nunca llega a ser por completo estable o realizado, y que cada intervención y cada movimiento generan un nuevo estado de devenir. Escribe: "Todos los bailarines se rehacen mediante los patrones que dictan". ${ }^{6}$

Mediante la aplicación de un lente crítico sobre las propuestas teóricas en torno a las relaciones entre especies de Haraway y otros dos teóricos, Matthew Calarco y Pau Patton, que abordan el devenir-con-animales, plantearé algunas preguntas más amplias acerca de la (inter)disciplina emergente de los estudios animales. De alguna manera, estos estudios han abordado la categorización de las relaciones humanas-no humanas precisamente como relaciones entre especies, y ésta es la razón de que a veces sean denominados estudios humano-animales. ${ }^{7}$ En la introducción a sus Zoografías Calarco reconoce que "no hay una definición ampliamente aceptada de lo que específicamente constituyen los estudios animales", pero "es claro que la mayoría de los autores y activistas que trabajan en esta disciplina comparten la convicción de que 'la pregunta por el animal' debe concebirse como uno de los problemas centrales en el discurso crítico contemporáneo". ${ }^{8}$ Los debates clave dentro de los estudios animales se centran así, por un lado, en el ser o (debido a la falta de una mejor palabra) la "naturaleza" de los animales y, por otro lado, en la posibilidad de efectuar la distinción humano-animal. ${ }^{9}$ En este ámbito, la pregunta de vivir-con, pero también la de vivir-como animales se vuelve central para la investigación en este campo.

Lo que me interesa aquí son las promesas y las limitaciones de la noción misma de interespecies o de ética de compañía, tal y como la desarrollan los teóricos de los estudios animales. Poniendo las cartas sobre la mesa: no seré demasiado optimista en cuanto a la viabilidad de un marco

\footnotetext{
${ }^{6}$ Haraway, When Species Meet, 25.

${ }^{7}$ Calarco, Zoographies, 3.

${ }^{8}$ Calarco, Zoographies, 1.

${ }^{9}$ Calarco, Zoographies, 2.
} 
o modelo ético como el que proponen esos estudios. Mi titubeo conceptual será trazado en el lienzo más amplio de lo que en trabajos anteriores llamé "bioética alternativa":

Tras abandonar la definición más aceptada de la bioética como el examen de asuntos éticos surgidos de las ciencias biológicas y médicas [...], la [b]ioética para mí significa una ética de la vida, donde la vida denota tanto la existencia física y material de organismos singulares (aquello que los griegos llamaron zoé) como su organización política en poblaciones (bios)..$^{10}$

Tradicionalmente, el debate bioético sobre asuntos de salud y gestión de la vida se ha enfocado en cuestiones de procedimiento, y se ha guiado por preguntas sobre la libertad moral, la influencia política y el interés económico, cuyas respuestas, sin embargo, ya están asentadas en muchos paradigmas dominantes de la ética que se ocupan de resolver los llamados dilemas morales en relación con las intervenciones genómicas, la cirugía cosmética y la clonación. En cambio, con base en la filosofía de la alteridad, la bioética "alternativa” no-sistemática que propongo tiene como punto focal la relación y el parentesco entre humanos y no-humanos (como los animales y las máquinas). Aun así, con todo y mi consideración de la relación entre especies y del reconocimiento de su importancia en tanto conjunto de circunstancias materiales y en tanto llamado a la ética, me abstengo de abrazar la ética de las especies acompañantes como una propuesta viable para (lo que de manera tentativa y cautelosa) llamamos hoy "era poshumana”. En el siguiente argumento trataré de dar una justificación a esta abstención ética de mi parte, elaborándola a través de tres puntos ciegos fundamentales que detecto en las trayectorias entrelazadas del pensamiento de los estudios animales:

\footnotetext{
${ }^{10}$ Joanna Zylinska, Bioethics in the Age of New Media (Cambridge: The MIT Press, 2009), XII-XIII.
} 
1. El punto ciego humanista, que se centra en las problemáticas del lenguaje, la cultura, el afecto y la violencia de su imposición. Podría argumentarse que la mayoría de lo que podemos llamar una gama de éticas de compañía entre especies termina retornando a lo humano por la puerta trasera. Ese retorno, por sí mismo, no es un gran problema, mientras sea reconocido como tal en vez de ignorado.

2. El punto ciego tecnicista, donde mucho trabajo se encamina hacia el reconocimiento del alma animal, es decir, su "subjetividad", de tal manera que el animal se convierte en una extensión del humano. Se ponen de relieve las entidades designadas como "humano" y "animal" a partir de un campo complejo de fuerzas técnicas co-constitutivas, para ser situados del lado de la "naturaleza".

3. El punto ciego violentista, donde la violencia se postula como enemiga de la ética, como una situación que debería ser superada por "nosotros" y por "el mundo", en lugar de ser vista como una condición estructural e inevitable de toda relación. ${ }^{11}$

La razón por la cual he decidido canalizar aquí mi discusión sobre las dificultades de las éticas de las especies acompañantes mediante el pensamiento de Haraway, Calarco y Patton no es porque posicione a estos pensadores como las figuras representativas de los estudios animales - aunque claro que ellos no podrían resistirse por completo a tal interpelación. Recurro a ellos principalmente porque en sus respectivos trabajos han dado pasos significativos para abordar, de manera más o menos explícita, los tres puntos ciegos arriba esbozados. En qué medida sus esfuerzos han sido exitosos y si es posible que nos ayuden a concebir mejores

\footnotetext{
${ }^{11}$ Los textos sobre estudios animales donde sus autores han realizado esfuerzos significativos para resituar los debates y discursos tradicionales sobre el animal más allá de los supuestos y sesgos antropocéntricos, pero han sido presas de al menos uno de los tres puntos ciegos indicados aquí incluyen a: Adams, Baker, Fudge y la obra The Companion Species Manifesto de Haraway, por citar algunos.
} 
maneras para vivir con otros no-humanos es algo que discutiré en el transcurso del texto. Terminaré con la propuesta tentativa de una bioética para el siglo xxI, una especie de propuesta en-las-nubes que rearticula las ideas de los estudios animales y las de pensadoras como Haraway, incluso si, en última instancia, lleva una o varias de sus nociones a una dirección diferente.

El libro de Haraway, When Species Meet, es una obra excepcional debido a su esfuerzo, tan riguroso como consistentemente juguetón, por socavar el excepcionalismo humano a través de una serie de exégesis filosóficas, reportes científicos, descripciones auto-etnográficas y anécdotas personales. También es un intento de poner en acto lo que podríamos describir como filosofía vivida, donde la teórica yace sobre la mesa para que todos observen tanto sus trayectorias intelectuales como sus intrincados deseos y pasiones. Tal acto de doble revelación no es enteramente nuevo: por bastantes décadas, feministas y teóricos queer han intentado incorporar pasiones, deseos y debilidades cotidianas a sus proyectos políticos e intelectuales, literal y figurativamente. De manera importante, Haraway está preparada para dirigir su propio lente crítico no sólo a sus propias ideas, sino también a sus prácticas cotidianas — como el entrenamiento de su perro Cayenne y su historia familiar- expone así las debilidades y contradicciones de cualquier "teoría vivida”. Es precisamente mientras tropieza y se enreda en los textos y texturas de los ambientes humanos-no humanos constituidos por académicos, perros, burócratas, el sol californiano, vino, competencias de entrenamiento, artículos de investigación, filósofos franceses y grandes y pequeñas tecnologías; que su argumento se vuelve más potente. 


\section{Puppy Love}

Haraway ha sido acusada con frecuencia de evadir cuestiones éticas en sus libros más tempranos, o de recurrir demasiado pronto al discurso legal estadounidense con sus sujetos morales y políticos claramente identificados e individualizados. Sin embargo, en sus últimas propuestas - principalmente en su texto de 2003, The Companion Species Manifesto- lleva a cabo un esfuerzo más explícito por esbozar una (bio)ética alternativa de vivir-con y emerger-con otros seres. Esta ética de especies acompañantes encuentra su origen en la experiencia vivida y se deriva de "tomarse las relaciones entre perros y humanos seriamente" ${ }^{12}$ El hábitat natural para estos actos de encuentro entre especies es ya desde siempre tecnológico. En su intento de pensar cómo vivir bien juntos, Haraway insiste en que la orientación de este proyecto ético tiene que trascender los deseos y anhelos del hombre como el único árbitro de "la bondad". En éste ejecuta uno de los gestos bien conocidos que tienden a dejar perplejos a varios de sus críticos, a mí incluida: a saber, propone "el amor" como la fuente de un lazo ético entre especies acompañantes. A pesar de diferenciarse con cuidado del narcisismo tecnofílico o caninofílico (es decir, de la creencia en que los perros son "herramientas" para la actividad humana o fuentes de afecto incondicional y de realización espiritual para los seres humanos), la noción de Haraway del amor como una coemergencia y cohabitación ética implica varios problemas. Uno, que no es el menor de ellos, es la manera en que los valores que subyacen en la ética de especies acompañantes — el amor, el respeto, la felicidad y el éxito- tienen un distintivo "toque" humano, precisamente porque es el ser humano quien le da a estos valores su definición y su adecuación para todas las especies complementarias. No hay escapatoria del dilema filosófico en que incluso el

${ }^{12}$ Donna J. Haraway, The Companion Species Manifesto. Dogs, people, and significant otherness (Chicago: Prickly Paradigm Press, 2003), 3. 
esfuerzo más comprometido de darles a los perros lo que ellos quieren y no lo que los humanos desean para ellos, depende inevitablemente de las ideas humanas de voluntad, satisfacción y regalo. Esto no significa que los perros deberían decirnos a "nosotros" lo que "ellos" quieren; sólo significa que una teoría del bien basada en valores no es la base más apropiada para este tipo de ética. ${ }^{13}$

En cierta medida, When Species Meet es una continuación del intento de Haraway de pensar una ética entre especies, pero de los desarrollos más significativos en este libro tiene que ver con la suspensión de cualquier insinuación pragmática, basada en valores, suspensión que sí estaba presente en el trabajo anterior de Haraway. Ahora, se muestra mucho más autorreflexiva y dubitativa. Para resaltar un hilo de su trabajo temprano, Haraway propone que "ser un ser humano situado es estar moldeado por y con animales familiares". ${ }^{14}$ Mientras que para ella esto es un hecho ontológico dado, una forma ética de estar-con requiere cierta curiosidad ante nuestra ontología y nuestro devenir — es decir, ante aquellos que no son nosotros pero que constantemente nos desafían a través de su mirada, su tacto o su lengüetazo.

\section{Sellado con un beso}

Haraway despliega sus exhortos éticos a la curiosidad animal — con probabilidad el material de construcción más delicado y, paradójicamente, el más fuerte para cualquier ética de cohabitación entre especiesmediante un encuentro con El animal que luego estoy si(gui)endo de Jacques Derrida, un texto a menudo citado dentro de los círculos poshumanistas. Aquí, Derrida relata encontrarse desnudo, observado y, por lo

\footnotetext{
${ }^{13}$ Algunas de las ideas incluidas en este párrafo las tomé prestadas de mi reseña "Dog’s R Us?” de Haraway, en parallax vol. 12, núm. 1, 129-131.

${ }^{14}$ Haraway, When Species Meet, 47.
} 
tanto, avergonzado por su propia gata, e insiste en que "el gato del que hablo es un gato real, verdaderamente, creedme, un gatito" ${ }^{15}$. Al comentar al respecto, Haraway describe sus propios afectos abiertamente: ama a su perro — "Hemos tenido conversaciones prohibidas; hemos tenido interacción oral" ${ }^{16}$ - y también le gusta Derrida. Sólo se muestra un poco preocupada sobre los sentimientos que este último pueda albergar para con su gata. De manera más precisa, Haraway se muestra decepcionada de que Derrida en última instancia utilice a su gata como escalón para una bella parábola filosófica sobre el no-saber humano, y por no tener una relación lo suficientemente íntima o curiosa con dicho animal. Haraway reprocha a Derrida que "no consideró seriamente una forma alternativa de compromiso... una que se arriesgara a saber algo más sobre los gatos y cómo devolverles la mirada, tal vez de manera científica, biológica y, por tanto, filosófica e íntima". ${ }^{17} \mathrm{El}$ propio Derrida admite de antemano la culpa, al confesar que "me sentí despojado delante de un pequeño ser vivo mudo y mi deseo confesado de escapar a la alternativa de la proyección apropiadora y de la interrupción cortante, todo esto deja adivinar que no estoy listo para interpretar o experimentar esa mirada fijada de un gato, sin una palabra, en mi desnudez por un gato..." ${ }^{18}$ En este preciso acontecimiento Derrida llegó justo al borde del respeto, pero luego se distrajo con su propia desnudez y su pajarito y, así, con su propio narcisismo filosófico-antropocéntrico. De este modo "fracasó en cumplir una simple obligación hacia las especies acompañantes: no desarrolló curiosidad acerca de lo que el gato podría de hecho estar haciendo, sintiendo, pensando, o tal vez facilitándole al mirarlo de vuelta esa mańana". En la lectura de Haraway, ese día Derrida "perdió

\footnotetext{
${ }^{15}$ Jacques Derrida, El animal que luego estoy si(gui)endo, traducción de Cristina de Peretti y Cristina Rodríguez (Madrid: Trotta, 2008), 20.

${ }^{16}$ Haraway, When Species Meet, 16

${ }^{17}$ Haraway, When Species Meet, 20.

${ }^{18}$ Derrida, El animal que luego estoy si(gui)endo, 34.
} 
una posible invitación, una posible introducción a otra manera de hacer-mundo". ${ }^{19}$

Ésta es una amonestación seria; una que como amante fracasada de los animales —es decir, como alguien que nunca ha tenido un perro, que no arrulla a los gatitos y que no tiene deseo alguno de salir a cabalgar - tomo de manera personal. Lo que quizá también es un signo del narcisismo ya mencionado (y de un humanismo sin reconstruir). Pero ¿qué si Derrida en realidad sí "sintió curiosidad”, pero más bien se negó a canalizar su curiosidad por medio de sus propias ideas imaginadas del deseo, el amor, el respeto y la compañía?

\section{El amor no es suficiente}

Las amonestaciones de Haraway no sólo van dirigidas a Derrida, sino también a otros teóricos y teóricas "metropolitanos" de persuasión crítica que (como yo) de alguna manera se hallan impedidos, por su propio corsé disciplinario y su educación urbana, para preocuparse por los animales de manera suficiente y adecuada. La incomodidad que ellas generan me plantea el importante asunto de lo que en realidad significa "deshacer la especie" en el encuentro con otra especie, y rehacerse después de un encuentro tal. ¿Es eso lo mejor que el poshumanismo podría esperar, donde el "post" se refiere al encuentro transformador entre especies en lugar de cualquier superación directa del humano ${ }^{20}$ En ese caso, ¿qué pasa si este animal no es un perro, un gato o un caballo de la familia de los animales domésticos amigables, y más bien se trata de un parásito, una bacteria o un hongo? (Por cierto, todos éstos también están incluidos en la noción de Haraway de especies acompañantes, incluso si no se en-

\footnotetext{
${ }^{19}$ Haraway, When Species Meet, 20.

${ }^{20}$ Haraway, When Species Meet, 21.
} 
cuentran propiamente como tal en sus escritos). En una reseña de When Species Meet, Boria Sax critica de manera similar a Haraway por mostrar "apenas algún interés en las criaturas salvajes, excepto cuando brindan oportunidades para exhibir la ingenuidad humana” ${ }^{21}$ El amor hacia la seńora Cayenne Pepper, que es como Haraway llama afectuosamente a su pastor australiano, parece desplazar la obligación de contar una historia de multiespecies con aquello que Derrida llama "singularidad insustituible", 22 y abre en cambio paso al mero particularismo o, en términos menos generosos, a deshacerse por el amor a las mascotas. En lugar de preocuparnos por superar la diferencia humano-animal a través de la experiencia compartida hacer-otros-mundos, ¿̇no deberíamos pasar más tiempo rastreando las diferencias ya "mundanizadas" entre animales, especies y categorías, y analizar no sólo cómo se despliegan sino también lo que significan? Por ejemplo, de acuerdo con la socióloga australiana Ann Game, los caballos pueden inducir reticencia o una familiaridad descuidada en quienes no los conocen. "Pero vivir relacionalmente con esos caballos —escribe Game- significa conocer y respetar su otredad y su diferencia, lo cual a cambio implica reconocimiento de la otredad en nosotros". 23

¿Qué deberíamos hacer entonces con el postulado de Calarco de que "la distinción humano-animal no puede y no debería ser mantenida"?24 Si por distinción nos referimos a la lista de diferencias estructurales que de manera segura acomodan a los seres en diversas categorías completamente discretas - Homo sapiens, Canis lupus familiaris, Erinaceus europaeus—, entonces tal vez hay buenas razones para suspender, al menos de forma temporal, tal tipología, en especial por la manera en que puede

\footnotetext{
${ }^{21}$ Boria Sax, "Human and Post-Animal: Review of Haraway, Donna J. 'When Species Meet", H-Nilas, H-Net Reviews, (abril de 2008) https://www.h-net.org/reviews/showrev.php?id=14416.

${ }^{22}$ Derrida, The Animal That Therefore I Am, 9.

${ }^{23}$ Anne Game, "Riding: Embodying the Centaur", Body and Society 7, núm. 4 (2001), 10.

${ }^{24}$ Calarco, Zoographies, 3.
} 
utilizarse para justificar la dependencia y explotación entre especies (incluso si eventualmente concluimos que las relaciones de poder definen la coexistencia humano-animal de manera inevitable). Aun así, el reconocimiento de un hueco entre lo humano y lo animal como categorías conceptuales a nuestra disposición es necesario, si es que no queremos caer demasiado fácil en un acrítico continuismo de especies, como el profesado por neodarwinistas como Richard Dawkins, quien sostiene que "nosotros" somos básicamente "animales". Estos teóricos ejercen todos sus privilegios cognitivos humanos por medio de la maniobra teórica de subsumir una categoría conceptual — por ejemplo, "lo humano" debajo de "lo animal" - . De la misma manera, la afirmación de Calarco sobre la necesidad de eludir "la distinción humano-animal" sólo puede realizarse desde el lugar de la diferencia entre especies.

Cuando Calarco sostiene que "la filosofía aún tiene un papel único e importante" en transformar "nuestro pensamiento sobre lo que llamamos animales", parece no percatarse de que su proposición reafirma la misma distinción que trata de superar. ${ }^{25} \mathrm{Al}$ describir como "dogmática" la resistencia de Derrida a "abandonar la distinción humano-animal", 26 Calarco revela y simultáneamente encubre su propio gesto de intentar seguir filosofando sobre el animal, incluso si se ve a este último como parte de un sistema amplio de materialidades co-emergentes. Ahora bien, no quiero entrar en una discusión sobre si el animal puede o no hacer filosofía, pues no estoy segura de que nos llevaría muy lejos. Sólo me propongo destacar el gesto diferencial y tajante de filosofar sobre el otro - un gesto singularmente diferente a, por ejemplo, comerse al otro. Por lo tanto, no resulta sorprendente que Derrida no haya abandonado esta distinción problemática y políticamente sensible. Después de todo, cualquier acto de "abandono" como éste debe ejecutarse desde la posición más

\footnotetext{
${ }^{25}$ Calarco, Zoographies, 4.

${ }^{26}$ Calarco, Zoographies, 145.
} 
antropocéntrica: no sólo desde el "Yo soy", sino también desde el "Yo decido" y "Yo profeso", con toda la autoridad hegemónica que esa posición conlleva. Lo que Calarco ve como la "negativa" de Derrida tal vez sólo se trata de vacilación, una que de hecho fortalece la contribución de Derrida a los animal studies. Pero incorporar ese momento de vacilación como condición de una ética responsable entre especies no es algo que Calarco y Haraway quieran, en particular, considerar. De manera significativa, al revisar el Cyborg Manifesto de Haraway en la penúltima página de su propio libro, Calarco considera como una exposición de hechos lo que evidentemente es una proposición normativa —a saber, que "el límite entre lo humano y lo animal está verdaderamente quebrantado"27-, una proposición que, por cierto, se mantiene desconectada de cualquier contexto material particular y que carga con toda la fuerza retórica de un "Yo" que es el que escribe, signa y quebranta. Calarco propone, de manera irónica, que una mejor solución a la "negativa" de Derrida se encuentra en la declaración final de Haraway según la cual "muchas personas ya no sienten la necesidad para tal separación" 28 (espero que no sea necesario explicar la burla involuntaria una vez que la puse en cursivas para usted, querido lector).

\section{No dejes que las estrellas se metan en tus ojos}

¿Hacia dónde partimos después de esto? ¿Qué tan lejos —ética y epistemológicamente- nos puede llevar esta vacilación sobre lo animal? Derrida nos brinda, de manera mucho más accidentada, pero, tal vez, mucho más responsable y pensada (en ese anticuado modo antropocéntrico), la siguiente sugerencia:

${ }^{27}$ Calarco, Zoographies, 140.

${ }^{28}$ Calarco, Zoographies, 140. 
una discusión no tiene ningún interés en cuanto a la existencia de algo como una discontinuidad, una ruptura e incluso un abismo entre aquellos que se denominan hombres y lo que los supuestos hombres, aquellos que se nombran hombres, denominan el animal. Todo el mundo está de acuerdo en esto, la discusión está cerrada de antemano y habría que ser más animal que los animales para dudar de esto. Los propios animales lo saben. [...] La discusión merece empezar cuando se trata de determinar el número, la forma, el sentido, la estructura y el espesor estratificado de este límite abisal, de sus bordes, de esta frontera plural y plegada varias veces sobre sí misma. La discusión se vuelve interesante cuando, en lugar de preguntarse si hay o no un límite discontinuo, se procura pensar lo que se transforma en un límite cuando es abisal, cuando la frontera no forma una sola línea indivisible sino más de una línea en abismo y cuando, y por consiguiente, no se deja ya trazar, ni objetivar, ni contar como una e indivisible. ¿Qué son los bordes de un límite que crece y se multiplica alimentándose de abismo? ${ }^{29}$

Desde aquí Derrida desarrolla una triple tesis que sostiene lo siguiente: (1) esta ruptura abismal no marca un distinción directa ni tajante entre dos entidades: hombre y animal; (2) la frontera de esta ruptura abismal tiene una historia que no podemos ignorar ni desestimar demasiado rápido; (3) más allá de la frontera de lo humano existe una multiplicidad heterogénea de lo vivo, o "una multiplicidad de organizaciones y relaciones dentro de los dominios que son cada vez más difíciles de disociar por medio de las figuras de lo orgánico y lo inorgánico, de la vida y/o la muerte". ${ }^{30}$

Tal vez haya una similitud entre lo que Derrida llama "una multiplicidad de organizaciones" de ámbitos indisociables y lo que Haraway entiende como la co-evolución y co-emergencia de lo orgánico y lo inor-

\footnotetext{
${ }^{29}$ Derrida, El animal que luego estoy si(gui)endo, 47.

${ }^{30}$ Derrida, The Animal That Therefore I Am, 31.
} 
gánico. Esta línea argumentativa también apunta hacia la dimensión técnica de estas ontologías múltiples, a través de las cuales los seres cobran vida por medio del proceso técnico de generación o creación, sin que ningún elemento fijo preceda a la mutua transformación de lo orgánico y lo inorgánico. No obstante, sugiero que incluso si consideramos la co-evolución y a la co-emergencia como puntos de partida para considerar las relaciones éticas entre especies y géneros, necesitamos llegar ahí mediante el desvío derrideano hacia preocuparse no sólo por otros seres y otras especies, sino también por la historia y el significado de los procesos de "igualar" y "alterizar". A su vez, esto requiere que no sólo reconozcamos "nuestro" parentesco con los animales, sino también con las máquinas, con la técnica. La responsabilidad ética representa la capacidad y la necesidad de responder — "quienes que responden son ellos mismos co-constituidos en el acto de responder" 31 - la cual aplica tanto para las personas como para los animales de laboratorio y los domésticos. También implica reconocer la inevitabilidad de las relaciones de dependencia entre humanos, animales y máquinas, algunas de las cuales incluyen causar dolor y muerte - aunque, como insiste Haraway, tales prácticas “jamás deberían dejar a sus practicantes en una cómoda seguridad moral, seguros de su rectitud". ${ }^{32}$

\footnotetext{
${ }^{31}$ Haraway, When Species Meet, 71.

${ }^{32}$ Haraway, When Species Meet, 77. Los perros y otros animales no llegan a nosotros desde una especie de mundo edénico: son actores y sujetos en las complejas redes tecnocientíficas de la producción tecnocapitalista. Haraway reconoce, siguiendo a Emund Russell, que los perros son "biotecnologías, trabajadores y agentes de la producción de conocimiento tecnocientífico en el régimen del capitalismo animado"; son pastores "seleccionados deliberadamente por sus capacidades de trabajo", trabajadores de trineos, trabajadores/competidores en las pruebas con ovejas y guardianes de ganado (56). Al igual que los humanos y otros seres del mundo, animados e inanimados, los perros coemergen mutuamente por medio de los múltiples procesos interconectados de la producción biotecnológica. Aun así, Haraway reconoce que los humanos son los que "realizan los planes deliberados para cambiar las cosas" (56) y, por lo tanto, son quienes definen el propósito y la dirección de muchos de estos procesos transformativos — así sea perros guía para los invidentes o entrenarlos para competir en deportes de agilidad_ incluso si, para lograr estos objetivos "los perros y las personas tienen que entrenar juntos en modos de cambio de sujeto" (57). Sin embargo, también argumenta que las personas y los perros "emergen como compañeros mutuamente adaptados en las culturas naturales del capitalismo activo", lo cual la guía a postular que deberíamos pensar mucho más sobre lo que ella denomina "valor de encuentro" (62). Este valor su-
} 
De lo anterior surge que la violencia y la dependencia se posicionan como condiciones inevitables de "hacer-mundo". Esta conclusión no debe verse como una cláusula para el abandono de la responsabilidad ética. El reconocimiento de la inevitabilidad de la violencia en cualquier relación con la alteridad no elimina el deber de minimizar esa violencia y reflexionar sobre ella. Una teoría ética que incorpora la violencia en su marco conceptual —en lugar de simplemente hacerla a un lado en un gesto fantasioso de purificación moral— promete abordar la cuestión de la dependencia en toda su complejidad. Ello no implica imponer una equivalencia moral entre todas las formas de violencia y todas las formas de dependencia, incluso si aceptamos que "[c]ualquier acto de identificación, denominación o relación es una traición y una violencia hacia el Otro". ${ }^{33}$ No obstante y a pesar de reconocer que no hay una posición ética "pura", "ninguna manera de vivir que no sea también la manera de alguien, y no sólo de algo, de otro modo muriendo diferencialmente", ${ }^{34}$ la propuesta de una ética entre-especies no utilitaria e "implacablemente mundana" finalmente suena un poco difusa cuando Haraway escribe que

[1] a moralidad necesaria, desde mi punto de vista, es cultivar una capacidad radical para recordar y sentir lo que está sucediendo y para poner en acto el trabajo epistémico, emocional y técnico para responder de manera práctica a la complejidad permanente que no está resuelta por las taxonomías jerárquicas y que no tiene garantías filosóficas, humanistas o religiosas. ${ }^{35}$

puestamente será diferente, dependiendo de si estamos lidiando con un perro o con un microbio. La existencia de tales economías de escala y ternura tan diferentes es una de las razones clave de por qué la ética entre especies guiada por principios y valores generales es muy difícil de diseńar.

${ }^{33}$ Calarco, Zoographies, 136. Al comentar sobre el pensamiento ético de Derrida, Calarco explica que la inevitabilidad de la violencia en cualquier relación con el otro "no debería interpretarse como que esa violencia es inmoral o que todas las formas de violencia son equivalentes. Más bien, el objetivo es socavar por completo la posibilidad de lograr una buena conciencia en relación con las preguntas de no violencia hacia el otro. El ideal de la pureza ética es descartado a priori como estructuralmente imposible".

${ }^{34}$ Haraway, When Species Meet, 79

${ }^{35}$ Haraway, When Species Meet, 75 
Al decir esto Haraway parece caer presa de aquello que Simon Glendinning llama la "presunción cognitiva" del humanismo, en el sentido de que los actos y procesos humanos de "recordar", "sentir lo que está pasando" y "actuar prácticamente" no han sido correctamente evaluados en cuanto a su antropocentrismo. ${ }^{36}$ De nueva cuenta, esto no supone decir que los humanos necesiten invitar a "otros" —animales o máquinas sintientes- a sus círculos de pensamiento, sentimiento y actuación: ese gesto sólo confirmaría la taxonomía jerárquica. Sólo se trata de sugerir que cierta duda o vacilación puede ser introducida en la fundación misma de una ética de las especies acompañantes. Sí, existe el peligro de que este ego dubito sólo sea una extensión del pensamiento y el razonamiento cartesianos. Sin embargo, para que también se trate de una ética de la alteridad, en lugar de reducirse fundamentalmente a una ontología del Yo, el resultado de la duda debe apuntar hacia otro lado. La duda ética tiene el potencial de desplazar el foco de la atención desde las especies hacia la alteridad que no está en mí. Es así que la duda ética no se pone al servicio de la reafirmación última del "Yo" humano.

Sin importar que yo defendiera el posicionamiento especial de un ser humano con su propia teleología y verdad, o el continuismo de las especies del naturalismo moderno, que afirma la diferencia de grado, no de clase, cualquier otra cosa necesitaría el reestablecimiento de la posición de conocer la naturaleza de la diferencia entre especies y de arbitrar dicha naturaleza de una vez por todas. Hay un valor ético en el precepto de sentir curiosidad por los "animales", pero esta curiosidad tendría que combinarse con el reconocimiento de que no conocemos tanto de "ellos". De lo contario, nos enfrentamos al peligro de que la curiosidad conduzca hacia la proyección de nuestras creencias, ideas y deseos menos pensados sobre "la alteridad animal". En esa proyección el conocimiento sería una mera extensión de lo que ya creíamos saber en primer lugar,

\footnotetext{
${ }^{36}$ Simon Glendinning, In the Name of Phenomenology (Londres y Nueva York: Routledge, 2007), 184.
} 
una filtración de algún comportamiento observable mediante el aparato cognitivo y conceptual que está a nuestra disposición, el cual también nos hace creer que hemos sido co-constituidos todos juntos — mientras que, de hecho, sólo hemos constituido a este "animal" en nuestra propia imagen (de "nosotros" y de "ellos"). El reconocimiento ético de la diferencia entre lo humano y lo animal no equivale, por tanto, a conocer su naturaleza de una vez por todas. De hecho, cualquier intento de dominarla cognitivamente sólo será una narrativa, una historia que tiene, inevitablemente, un carácter místico. También será una prótesis técnica más - junto con las herramientas de piedra, los martillos y las computadoras- de las que dan forma a nuestra co-emergencia sistémica en y con el mundo. ${ }^{37}$

\section{Sillita de lado}

Si las historias y los mitos moldean al ser humano tanto como las herramientas técnicas y los aparatos, una historia de particular interés en el contexto de la ética entre especies tiene que ver con el entrenamiento animal narrado por Haraway y Paul Patton. Al reflexionar sobre el entrenamiento de Cayenne para competencias de alto rendimiento, Haraway se muestra consciente de la economía de clase, ocio y geografía que configura la práctica del entrenamiento animal. También reconoce que es el ser humano quien decide llevarla a cabo, aunque "[e]l humano deba

\footnotetext{
${ }^{37}$ En La técnica y el tiempo, volumen 1, Bernard Stiegler recurre a las teorías paleontológicas de André Leroi-Gourghan para argumentar que el humano es originalmente prostético, es decir, dependiente de prótesis técnicas para su emergencia y existencia. Para Stiegler el impulso hacia la exteriorización, hacia las herramientas, la artificiosidad y el leguaje es debido a una tendencia técnica que ya existía en la dinámica zoológica más antigua. Debido a esta tendencia el (aún no) humano se levanta y alcanza aquello que no está en él o en ella: y es mediante la reflexividad conceptual y visual (verse a sí mismo en la cuchilla de piedra, memorizar el uso de la herramienta) que emerge como relacionado con la alteridad que no es parte suya. Para ver más sobre las consecuencias de esta línea de pensamiento para nuestra idea de ética, se puede revisar Bioethics in the Age of New Media, 35-63.
} 
[entonces] responder a la autoridad del desempeño del perro" 38 y, por lo tanto, considerar aquello que Game llama "sociabilidad" animal (o, para ser más precisos, sociabilidad equina). ${ }^{39}$ Pero, si reconocemos junto con Game, que en cualquier situación de entrenamiento los animales necesitan "permitirles a las personas ser guiados", ${ }^{40}$ también necesitamos advertir el problema de temporalidades múltiples — la diferencia entre el presente animal y el futuro humano, que también es una diferencia entre necesidad (estratégica) y conveniencia. Haraway admite haber tenido las mismas reservas que muchos teóricos culturales respecto al perfeccionamiento de la especie para "producir perros que pudieran proteger rebaños con una habilidad inigualable, ganar en conformación, sobresalir en la obediencia y en los deportes de agilidad, y servir dignamente como mascotas", pero aparentemente cambió de opinión cuando "se enamoró". ${ }^{41}$ Ahora bien, debemos interpretar esta confesión menos como un reconocimiento de que lo que Haraway llama el "amor a la raza" ha nublado su juicio ético-crítico, y más como la admisión de estar con, entre y cerca de los animales. En este sentido se trata de una amonestación contra los teóricos críticos (como yo, tal vez) que sólo ven a los animales desde lejos, al tratarlos como objetos de interpretación y reductibles a figuras retóricas bidimensionales. Haraway parece decirnos: algunos de ustedes saben cómo pensar con animales, pero en realidad no saben cómo vivir con ellos —y realmente qué hacer con ellos.

Preocupaciones similares apuntalan el intento de Paul Patton por pensar la filosofía animal desde el abajo o, más bien, desde la silla. Su ensayo "Language, Power, and the Training of Horses", publicado en Zoontologies, la colección editada por Cary Wolfe, comienza con una declaración genérica de amor animal: "las personas aman a los caballos por todo

\footnotetext{
${ }^{38}$ Haraway, When Species Meet, 221.

${ }^{39}$ Game, Riding: Embodying the Centaur, 4.

${ }^{40}$ Game, Riding: Embodying the Centaur, 4.

${ }^{41}$ Haraway, When Species Meet, 129.
} 
tipo de razones". ${ }^{42}$ El mismo Patton se enamoró de los caballos al aprender a entrenarlos. Como Haraway, Patton intenta combinar su posición arraigada en la filosofía continental con una "buena historia" sobre su relación con su caballo Flash. Lo que en mi opinión le falta a su narrativa es una reflexión más profunda sobre el deseo mismo de entrenar a Flash y, por lo tanto, de dominar a otro ser, y sobre el placer que ahí se pone en juego. Incluso si reconocemos que la precisión en el entrenamiento implica hacer que el caballo "haga lo correcto", esto no explica por qué "nosotros" querríamos lograr algo así en primer lugar. ¿Cuál es el propósito del entrenamiento? El argumento sobre el ennoblecimiento, tomado de la entrenadora de caballos Vicky Hearne, que Haraway saca a relucir por la rúbrica del florecimiento y al que Patton también se refiere, es demasiado cercano a las narrativas coloniales de mejorar lo nativo, para mi propio y precario confort de amante de los animales. Claro que Haraway y Patton no son ajenos a la teoría poscolonial. Patton también se da cuenta de que:

[1]a defensa estético-moral de las actividades para las que son entrenados los animales está corrompida [...] en la medida en que distorsiona aquello que, antropomórficamente, podríamos llamar los "valores" de los animales involucrados y proyecta en ellos aptitudes y aires que son valorados por sus entrenadores demasiado humanos como si fueran naturales. ${ }^{43}$

¿Cómo logra Patton eludir la acusación potencial de que, mediante la práctica del entrenamiento animal, lo que hace es racionalizar ciertas preferencias humanas y deseos culturalmente adquiridos por la belleza, gracia y destreza? Temo que no lo logra muy bien, como se evidencia en la siguiente declaración: "las relaciones disciplinarias de mando y obe-

\footnotetext{
${ }^{42}$ Paul Patton, "Language, Power, and the Training of Horses" en John Protevi y Paul Patton editores. Between Deleuze and Derrida (Londres y Nueva York: Continuum, 2003), 83.

${ }^{43}$ Patton, "Language, Power, and the Training of Horses", 93.
} 
diencia son precisamente un medio para crear y mantener relaciones civiles y estables entre diferentes seres, no sólo entre individuos de la misma especie, sino también entre representantes de diferentes especies" ${ }^{44}$ Conceder, tras Nietzsche y Foucault, que todas las relaciones sociales son relaciones de poder, no soluciona el dilema sociopolítico de que las relaciones sociales no son iguales entre sí; no todas significan lo mismo y no todas se dan necesariamente de la misma manera. Por ejemplo, ¿cómo se llegó a la decisión de que entrenar a los caballos es algo bueno? No me persuade de un modo particular la justificación más espiritualista de Game según la cual el entrenamiento humano-equino es una manera de vivir juntos de forma más "creativa". ${ }^{45}$ Mientras que la mayoría de nosotros con probabilidad estaría de acuerdo en que el entrenamiento de caballos no es moralmente equivalente a golpear caballos o comérselos, también me pregunto cuál es el criterio que respalda la noción de "civilidad" que estructura la declaración de Patton y cómo llegó a ella. Patton dice que con el entrenamiento animal aprendemos "que las formas jerárquicas entre desiguales no son incompatibles con las relaciones y obligaciones éticas hacia otros seres". ${ }^{46}$ Pero este argumento tiene que desarrollarse más por medio de la noción de la singularidad de las especies, pues al olvidar esta última sólo se perpetuaría el excepcionalismo de las especies que Haraway y Patton tratan de evitar. Al preguntarme por el propósito del entrenamiento no estoy, por tanto, promoviendo una suerte de fantasía edénica donde lobos y yeguas deambulan libremente. Sólo sugiero que es necesaria una aclaración respecto a las inversiones afectivas de los amantes de los animales y los teóricos de los estudios animales. La reflexión sobre el deseo del entrenador de hacer que el universo se doblegue bajo su mando es algo que Haraway y Patton evitan, a pesar de todo, en sus análisis afectivos sobre las relaciones hu-

\footnotetext{
${ }^{44}$ Patton, "Language, Power, and the Training of Horses", 95.

${ }^{45}$ Game, Riding: Embodying the Centaur, 7-8.

${ }^{46}$ Patton, Language, Power, and the Training of Horses, 95.
} 
mano-animales. Incluso si reconocemos, como Patton lo hace, que la relación de entrenamiento es una forma posible de relación ética que "realza el poder y el sentimiento de poder tanto del caballo como del jinete", ${ }^{47}$ estamos de regreso en el circuito de la fantasía y la proyección teórica que recubre la violencia de hacer mundo y hacer sentido en el mundo con y por medio de los animales.

\section{¿Qué hay de nuevo, pussycat? Bioética de otro modo}

¿Hay una salida? Como he intentado demostrar, cualquier gesto de proponer una ética, de manera inevitable, se encuentra suspendido entre el antropocentrismo y la violencia. El reconocimiento de que esto es así no debería, sin embargo, absolvernos de la responsabilidad ética de buscar mejores alternativas para vivir-con (o convivir) — con animales, con otros humanos y con máquinas. Al tiempo que las biotecnologías y los medios digitales constantemente desafían nuestras ideas establecidas de lo que significa ser humano y vivir una vida humana, también imponen una transformación de los códigos morales mediante los cuales entendemos la vida, y un replanteamiento de quién es el sujeto moral en la actual coyuntura. La crítica poshumanista discutida en este ensayo tiene el potencial de cuestionar el sesgo antropocéntrico de nuestras formas de pensar establecidas — es decir, la creencia de que el humano se sitúa en la cima de la "cadena de seres" y que esta posición privilegiada le da el derecho de tener una serie de actitudes consumistas y explotadoras hacia los seres no-humanos (mamíferos, peces, el bosque, la esfera ecológica como un todo, etcétera). De acuerdo con Haraway et al., el ser humano puede en cambio entenderse como parte de una compleja red técnico-natural

\footnotetext{
${ }^{47}$ Patton, Language, Power, and the Training of Horses, 97.
} 
y como un ser que emerge de ella dinámicamente. En esta emergencia al ser humano se le presenta la tarea ética de decidir, siempre en un terreno incierto, sobre la vida en todas sus diferentes encarnaciones y actos.

En la era biodigital, este humano tentativamente diferenciado debe responder a un ámbito expandido de obligaciones, que van más allá de aquellas ejercidas por otros humanos singulares. La bioética lidia no sólo con preguntas sobre la transformación de la vida en un nivel biológico — por medio de la genómica, las secuencias de ADN, la clonación, entre otras situaciones-, sino también con la vida situada en un contexto político más amplio, a través de preguntas sobre el financiamiento de la industria biotecnológica, la gestión de las bases de datos de los sistemas de inmigración y asilo, la regulación de la cirugía cosmética, la vigilancia nacional y celular, la biociudadanía, etcétera. La toma de decisiones por parte de quienes se autodenominan "humanos", con toda conciencia de la carga histórica y cultural de este término, y de la naturaleza temporal y frágil de cualquier identificación humana, es importante para cualquier situación donde estén en juego los problemas de la vida y sus múltiples transformaciones. Implicarse en esa toma de decisiones, sin embargo, no tiene que equipararse a una celebración de superioridad humana: más bien, debería concebirse como una movilización práctica de las capacidades humanas de reflexión e intervención críticas, pese a que dichas capacidades estén limitadas y sean imperfectas. Ahora bien, la pregunta de si los "animales" o las "máquinas" deberían también implicarse en los procesos éticos es irrelevante, incluso si reconocemos que las características y los comportamientos que eran vistos como exclusivos del humano últimamente han sido identificados en otras especies. Es irrelevante porque la responsabilidad ética siempre sólo se refiere a "mî": es decir, a un ser humano singular, temporalmente estabilizado, que emerge en relación con otros humanos y no-humanos.

El dilema moral, que a veces surge en el contexto de la ética inter-especies, ante si "nosotros" deberíamos respetar a los pericos, a las bacterias, 
a los cyberdogs o incluso a los iPods muestra una reticencia a someter esta categoría de "nosotros", con toda su implícita unidad y especismo, a una crítica rigurosa. De la misma manera, en el marco conceptual esbozado en este ensayo, la ética no se trata tanto de respeto, porque el respeto asume que yo ya estoy por completo constituido como un agente moral antes de encontrar al otro, cualquiera que sea; después de esto puedo ofrecerle el regalo de mi reconocimiento, de mi cuidado y mi bondad a este otro. En cambio, la ética puede ser enseñada de una manera más productiva en términos fenomenológicos de capacidad para responder y para responder moralmente. Esta posición asume que cualquier actitud que yo adopte hacia el otro ya de antemano da respuesta a la presencia y la demanda del otro. ${ }^{48}$ De hecho, reservarse el respeto puede en ocasiones ser la acción más responsable, dependiendo de las circunstancias. También vale la pena enfatizar de nuevo que la noción del ser humano — que tan pronto como acepta la responsabilidad ética, se diferencia a sí mismo de las zanahorias, de las máquinas y del flujo general de la vida — no desaparece por completo en esta bioética "alternativa”, incluso si con ella planteamos algunas preguntas sustanciales a otras posiciones, preguntas que desafían los presupuestos humanistas y antropocéntricos compartidos por mucha de la bioética tradicional.

\footnotetext{
${ }^{48}$ De manera general, el marco conceptual filosófico para entender la ética en este sentido lo brinda el trabajo de Emmanuel Levinas y la lectura que Derrida hace de éste. La teoría ética de Levinas cambia el punto focal y la preocupación por el Yo al otro y, por lo tanto, puede ser leído como un golpe al egocentrismo del humano. El lugar que ocupo en el mundo para Levinas nunca es sólo mío. De manera contraria, pertenece al otro, a quien tal vez oprimí, hice pasar hambre o lo ahuyenté de mi hogar, mi país y mi vida. Su pensamiento da una justificación para preocuparse por la vida, cualquier vida, del otro, especialmente por las vidas precarias y desamparadas de todos aquellos que no tienen reconocimiento en el debate y en las políticas dominantes; también por aquellos cuya existencia biológica y política está confinada a "zonas de excepción": pacientes comatosos, quienes buscan asilo, refugiados, personas con cuerpos y apariencias no normativos, víctimas de la experimentación biotécnica. Sin embargo, recurrir a Levinas en un esfuerzo por desarrollar una bioética poshumanista es problemático, pues su teoría sufre de un sesgo antropológico, el cual es evidente, por ejemplo, en el peso excesivo que le da al lenguaje humano. Por lo tanto, su noción del otro necesita ser expandida si, en la era digital, ya no podemos estar seguros de si el otro que está ante mí es humano o máquina y si la "fraternidad" de la que habla Levinas se extiende a todas las familias de ADN (chimpancés, perros, bacterias). Discuto la viabilidad de la filosofía de Levinas para pensar una bioética de las relaciones humanas y no-humanas en Bioethics in the Age of New Media.
} 
Así entendida, la bioética alternativa se ofrece como un suplemento a la moral y la política, una demanda previamente dirigida a quienes nos llamamos humanos para que respondamos a la diferencia del mundo de forma crítica y responsable, sin recurrir demasiado pronto a verdades a medias, opiniones, creencias y estrategias políticas preestablecidas. Sin embargo, la bioética en este sentido no es algo que pueda ser "implementado" en definitiva o que se pueda convertir en una herramienta práctica para resolver dilemas morales específicos sobre la vida y la muerte. Tampoco puede reducirse a un solo "ejemplo", porque al convertirse en una vara de medición dicho ejemplo controlaría y colonizaría inevitablemente la necesidad de un trabajo crítico con apertura de horizontes. ${ }^{49}$ $\mathrm{Al}$ emprender este trabajo crítico-creativo de la bioética, me interesa más desplazar los parámetros del debate ético desde un paradigma moral individualista y solucionista donde las reglas pueden ser racional y estratégicamente elaboradas a partir de un principio previamente acordado, hacia un contexto político más amplio donde las decisiones individuales siempre están involucradas en relaciones complejas de poder, economía e ideología.

$\mathrm{Al}$ apuntar a un lugar de diferencia como un sitio productivo de relacionalidad y parentesco entre especies, la manera en que concibo a la bioética es capaz de desafiar al sistema jerárquico de la descendencia que tradicionalmente ha informado los modos de pensar acerca de las relaciones entre especies y formas de vida. Al mismo tiempo, al centrarnos en las múltiples instancias en que esta diferencia se manifiesta, siempre de forma distinta, es una manera de garantizar que no asimilemos varios seres y formas de vida a un flujo indiferenciado de la vida, para luego continuar filosofando como si nada hubiera pasado. Por lo tanto, esta

\footnotetext{
${ }^{49}$ Dicho esto, en varios de mis escritos he tratado múltiples escenarios y eventos bioéticos que surgen en el contexto de la cirugía cosmética, el aborto, la clonación, experimentos genéticos o prácticas artísticas que utilizan material biológico. De la misma manera, he sugerido maneras para pensar éticamente sobre todos estos casos.
} 
bioética no normativa y consciente de la técnica necesita considerar seriamente las relaciones polivalentes de la coevolución y la coemergencia. También tiene que conllevar una huella visible de reflexión durante el proceso mismo de su creación: desde la perspectiva humana del leguaje, la filosofía y la cultura. En otras palabras, esta bioética consciente de la técnica conlleva un exhorto a dar cuenta de la violencia de pensar la ética, incluso la ética de las relaciones entre especies.

Es importante puntualizar que la duda debe convertirse en la condición y en el dispositivo estructural de este otro tipo de bioética. No se trata de la duda imparcial del ego cogito cartesiano, sino de la suspensión de la posición esencialista de quien sabe de antemano, y demasiado precipitadamente, la naturaleza de la diferencia entre especies. Inclusive si esto suena como una propuesta ética mucho más tentativa y vacilante que algunas discutidas en este ensayo (sin mencionar muchas otras teorías bioéticas procesuales o basadas en el valor, donde a las distintas formas de vida les son asignados valores por adelantado para, posteriormente, ser ponderadas entre sí), tal vez puede ser más convincente para quienes no experimentamos amor por los animales de modo espontáneo o "natural". También puede mantener la vigilancia crítica ante esos expertos en estudios animales que aman, quizá demasiado, a sus especies acompañantes, o incluso a sí mismos como especies acompañantes. Ello porque la pregunta que se nos plantea no es sólo: "¿qué quiere mi mascota?” y ni siquiera es la pregunta cartesiana “quién soy yo?”; sino que también, y quizá antes que ninguna otra: “¡y qué si una bacteria me respondiera?"

\section{Referencias}

Calarco, Matthew. Zoographies: The Question of the Animal from Heidegger to Derrida. Nueva York: Columbia University Press, 2008. 
Derrida, Jacques. El animal que luego estoy si(gui)endo. Traducción de Cristina de Peretti y Cristina Rodríguez. Madrid: Trotta, 2008. Derrida, Jacques. The Animal That Therefore I Am. Traducción de Marie-Louise Mallet. Nueva York: Fordham University Press, 2008.

Game, Anne. "Riding: Embodying the Centaur". Body and Society 7, núm. 4 (2001).

Glendinning, Simon. In the Name of Phenomenology. Londres y Nueva York: Routledge, 2007.

Haraway, Donna. When Species Meet. Minneapolis y Londres: University of Minnesota Press, 2008.

Patton, Paul. "Language, Power, and the Training of Horses" en John Protevi y Paul Patton editores, Between Deleuze and Derrida. Londres y Nueva York: Continuum, 2003.

Sax, Boria. "Human and Post-Animal: Review of Haraway, Donna J. When Species Meet", H-Nilas, H-Net Reviews, abril de 2008, http://www.h-net.org/reviews/showrev.php?id=14416

Zylinska, Joanna. Bioethics in the Age of New Media. Cambridge: The MIT Press, 2009. 